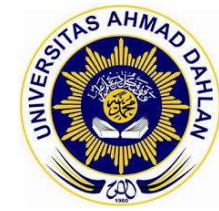

BERKALA FISIKA INDONESIA Jurnal IImiah Fisika, Pembelajaran dan Aplikasinya

http://journal.uad.ac.id/index.php/BFl/index 2085-0409 (Print) |2550-0465 (online)

\title{
Prototype perancangan geometri lengkung pada interchange konektivitas jalan tol
}

\section{Ety Dwiastuti ${ }^{1 *}$, Moh. Toifur ${ }^{2}$}

1,2 Magister Pendidikan Fisika, Fakultas Keguruan dan Ilmu Pendidikan, Universitas Ahmad Dahlan, Indonesia Email: etydwiastuti@gmail.com*

* Penulis korespondensi

\begin{tabular}{ll}
\hline \multicolumn{2}{l}{ Informasi artikel } \\
\hline Sejarah artikel: & \\
Dikirim & $16 / 03 / 21$ \\
Revisi & $11 / 04 / 21$ \\
Diterima & $14 / 04 / 21$ \\
\hline
\end{tabular}

Kata kunci:

Perancangan geometri lengkung

Interchange

Simulasi

Curved Geometry Design Interchange

Simulation

\section{Keywords:}

\begin{abstract}
ABSTRAK
Perancangan geometri jalan terutama dimaksudkan untuk menjaga keselamatan dan kenyamanan pengguna jalan. Interchange (simpang susun) jalan tol biasanya berupa tikungan dengan kemiringan tertentu yang dirancang agar pengemudi merasa nyaman dan aman saat kendaraan yang dikemudikannya bergerak melintas dengan kecepatan rata-rata aman. Penelitian ini mensimulasikan parameter-parameter koefisien gesek melintang antara permukaan jalan dengan ban $\left(\mu_{s}\right)$, kemiringan melintang $(\tan \theta)$, kecepatan rencana $(v)$, jarijari tikungan $(R)$ dan derajat kelengkungan tikungan $(\delta)$ menggunakan software Excel. Pada koefisien gesekan melintang $\left(\mu_{s}\right)$ tetap, kendaraan yang bergerak makin cepat di sebuah tikungan memerlukan jari-jari tikungan $(R)$ yang besar. Agar kendaraan tidak slip keluar dari jalur maka jalan dibuat semakin miring. Kemiringan jalan menahan kekuatan gaya sentrifugal yang menyebabkan kendaraan slip.
\end{abstract}

This is an open access article under the CC-BY-SA license

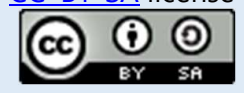

\section{ABSTRACT}

Curved geometry design prototype at toll road connectivity interchange. The road geometry design is primarily intended to maintain the safety and comfort of road users. Toll road interchanges are usually in the form of bends with a particular slope designed to make drivers feel comfortable and safe when their driving moves across at a safe average speed. This study simulates the parameters of the transverse friction coefficient between the road surface and the tire $\left(\mu_{\mathrm{s}}\right)$, the transverse slope $(\tan \theta)$, the design speed $(v)$, the radius of bend $(R)$ and the degree of angle $(\delta)$ using Excel software. At a fixed transverse coefficient of friction $\left(\mu_{\mathrm{s}}\right)$, a vehicle that is moving faster at a turn requires a large radius of the curve $(R)$. So that the vehicle does not slip out of the lane, the road is made more tilted. The slope of the road withstands the centrifugal force that causes the vehicle to slip.

\section{How to Cite:}

Dwiastuti, E., \& Toifur, M. (2021). Prototype perancangan geometri lengkung pada interchange konektivitas jalan tol. Berkala Fisika Indonesia: Jurnal Ilmiah Fisika, Pembelajaran dan Aplikasinya, 12(2), 33-39. 


\section{Pendahuluan}

Interchange (simpang susun) adalah persimpangan jalan yang tidak sebidang di mana mobilalat transportasi umum dapat lewat dari satu jalur ke jalur lainnya tanpa berhenti (Bryniarska \& Zakowska, 2017). Interchange biasanya berupa tikungan yang dirancang agar pengemudi merasa nyaman dan aman pada saat kendaraan yang dikemudikannya bergerak melewati tikungan dengan kecepatan ratarata aman. Dengan adanya interchange akan mempersingkat waktu tempuh kendaraan dari satu daerah ke daerah lain yang terhubung jalan tol (Lucietti et al., 2016). Interchange mengotimalkan konektivitas jalan tol.

Menurut Permen PU No. 19/PRT/M/2011, kecepatan terendah yang diizinkan di jalan tol Indonesia adalah $60 \mathrm{~km} / \mathrm{jam}$. Batas kecepatan maksimum $80 \mathrm{~km} / \mathrm{jam}$ untuk tol dalam kota dan 120 $\mathrm{km} / \mathrm{jam}$ untuk tol luar kota. Batas kecepatan ini ditetapkan dengan pertimbangan ketika terjadi pengereman mendadak masih ada waktu untuk mengambil tindakan. The American Association of State Highway and Transportation Officials (AASHTO) menetapkan standar keamanan waktu tanggap seorang pengemudi sebesar 2,5 detik sebelum mengambil tindakan (McGee, 1983).

Geometris jalan adalah konstruksi jalan raya yang mencirikan bentuk atau ukuran jalan raya, termasuk penampang, ruas memanjang, dan ciri-ciri lain dari bentuk fisik jalan (Bethary et al., 2016; Kaharu et al., 2020). Perancangan geometri jalan, antara lain meliputi parameter kecepatan rencana dan gaya-gaya yang bekerja. Kecepatan rencana adalah kecepatan kendaraan yang menopang desain teknologi geometri jalan dan memungkinkan mobil melaju dengan aman dan nyaman (Bethary et al., 2016; Subkhan, 2019). Ini adalah kecepatan maksimum yang dapat dicapai mobil saat melakukan perjalanan tanpa penundaan dan dengan aman. Dengan anggapan tersebut dapat dianalisis gaya-gaya yang bekerja pada kendaraan saat bergerak di tikungan jalan yang memiliki kemiringan.

Salah satu penyebab terjadinya kecelakaan di jalan raya adalah ketidaktepatan perancangan geometri jalan (Adnan et al., 2020; Arbaiyah et al., 2013; Intini et al., 2019; Ng \& Sayed, 2004). Biasanya sebelum melalui sebuah tikungan terdapat peringatan bagi pengemudi untuk mengendarai kendaraan pada kecepatan rata-rata aman. Pengemudi yang mengendarai kendaraan pada kecepatan rata-rata aman tidak akan mengalami slip yang disebabkan oleh efek gaya sentrifugal pada saat melalui sebuah tikungan (Erga Rahmada Fauzan et al., 2013).

Sumarsono, dkk. (2010) telah meneliti pengaruh alinyemen horizontal (horizontal alignment) dalam desain geometri jalan raya terhadap terjadinya kecelakaan lalu lintas di tikungan. Hasil penelitian menunjukkan tingkat kecelakaan akan turun jika radius tikungan lebih besar dari rata-rata radius tikungan jalan yang diamati. Dalam perancangan geometri jalan, alinyemen horizontal antara lain meliputi gaya sentrifugal dan bentuk tikungan.

Menurut standar Indonesia, derajat kelengkungan (dalam satuan ${ }^{\circ}$ ) adalah besaran sudut lengkung yang menghasilkan busur sepanjang 25 meter. Dalam perancangan, semakin besar nilai $R$ 
maka nilai $\delta$ semakin kecil, bentuk tikungan cenderung tumpul. Sebaliknya, jika nilai $R$ menurun maka nilai $\delta$ bertambah, bentuk tikungan menjadi lebih tajam (Suwardo et al., 2018).

Mobil yang melewati tikungan akan mengalami gaya sentrifugal. Apabila gaya-gaya penahannya lebih kecil dari pada gaya sentrifugal maka mobil dapat mengalami slip. Kajian gaya sentrifugal pada mobil yang bergerak menikung memberikan informasi adanya hubungan antara ukuran jari-jari tikungan $(R)$ dengan parameter-parameter kecepatan rencana $(v)$, kemiringan melintang jalan $(e)$, dan koefisien gesek melintang permukaan jalan dengan ban ( $f$ ). Selain itu akan diperoleh ukuran derajat lengkung tikungan $(\delta)$, yaitu besarnya sudut yang menghasilkan panjang busur 25 meter sebagai acuan dalam perancangan geometri jalan (Sinaga et al., 2019).

\section{Metode}

Penelitian ini menggunakan metode penelitian eksperimen yang dikerjakan secara komputasi. Dari persamaan (1) dan (2) dapat ditentukan variabel penelitian ini yaitu kecepatan rencana ( $v$ ) sebagai nilai yang ditetapkan terlebih dahulu (variabel kontrol), kemiringan melintang jalan $(\tan \theta)$ dan koefisien gesekan melintang $\left(\mu_{s}\right)$ sebagai nilai yang diubah-ubah (variabel bebas), serta jari-jari tikungan $(R)$ sebagai nilai yang dicari (variabel terikat). Setelah $R$ diperoleh dapat dihitung nilai derajat kelengkungan $(\delta)$.

$$
\begin{aligned}
& R=\frac{v^{2}}{127\left(\tan \theta-\mu_{s}\right)} \\
& R=\frac{v^{2}}{127\left(\tan \theta+\mu_{s}\right)}
\end{aligned}
$$

Data disimulasikan dengan Excel dengan cara koefisien gesekan melintang $\left(\mu_{s}\right)$ dibuat tetap, kemudian menentukan kemiringan melintang jalan $(\tan \theta)$, memvariasi nilai kecepatan rencana $(v)$, untuk memperoleh nilai jari-jari tikungan $(R)$ dan derajat kelengkungan $(\delta)$. Selanjutnya, koefisien gesekan melintang $\left(\mu_{s}\right)$ dibuat tetap berdasarkan hasil penelitian TEH (1992) dalam (Suwardo et al., 2018) yang disajikan dalam Gambar 1.

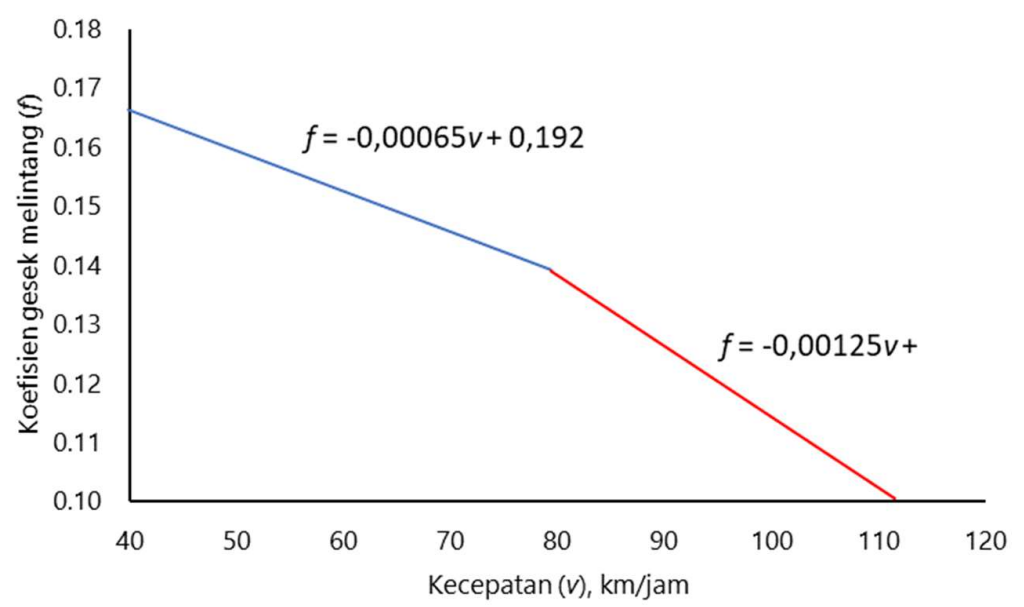

Gambar 1. Koefisien gesekan melintang maksimum. 
Pada penelitian ini, digunakan $\mu_{s}=0,15$. Kemiringan melintang jalan $(\tan \theta)$ berdasarkan data Bina Marga, 1997 pada rentang $\tan \theta=0,08-0,1$. Dalam simulasi digunakan 0-0,1, dimana 0 berarti jalan datar, sementara 0,1 adalah kemiringan melintang maksimum. Kecepatan rencana ditetapkan dari sumber data perancangan geometri jalan Permen PU No. 19/PRT/M/2011 dan Standar BM No. 007/BM/2009, seperti pada Tabel 1. Sedangkan Tabel 2 merupakan kecepatan rencana minimal jalan bebas hambatan.

Tabel 1. Kecepatan rencana jalan bebas hambatan.

\begin{tabular}{lccc}
\hline \multirow{2}{*}{ Fungsi jalan } & \multicolumn{3}{c}{ Kecepatan rencana, km/jam } \\
\cline { 2 - 4 } & Datar & Perbukitan & Pegunungan \\
\hline Jaringan jalan primer & $80-120$ & $70-110$ & $60-100$ \\
Jaringan jalan sekunder & $80-120$ \\
\hline \multicolumn{3}{c}{ *Sumber: Permen PU No. 19/PRT/M/2011 }
\end{tabular}

Tabel 2. Kecepatan rencana minimal jalan bebas hambatan.

\begin{tabular}{lcc}
\hline \multicolumn{1}{c}{ Medan jalan } & \multicolumn{2}{c}{ Kecepatan rencana minimal, $\mathbf{~ k m}$ /jam } \\
\cline { 2 - 3 } & Antar kota & Perkotaan \\
\hline Datar & 120 & $80-100$ \\
Perbukitan & 100 & 80 \\
Pegunungan & 80 & 60 \\
\hline & *Sumber: Standar BM No. 007/BM/2009
\end{tabular}

Berdasarkan data tersebut, kecepatan rencana yang dipakai pada penelitian ini sebesar $60-120$ $\mathrm{km} / \mathrm{jam}$. Hasil analisis kuantitatif menggunakan simulasi Excel. Dari penggambaran grafik dapat dilakukan analisis kualitatif untuk mengetahui pola perancangan geometri lengkung jalan.

\section{Hasil dan Pembahasan}

Hasil simulasi gerak kendaraan pada kecepatan rencana minimum ditampilkan dalam Gambar 2 dan 3.

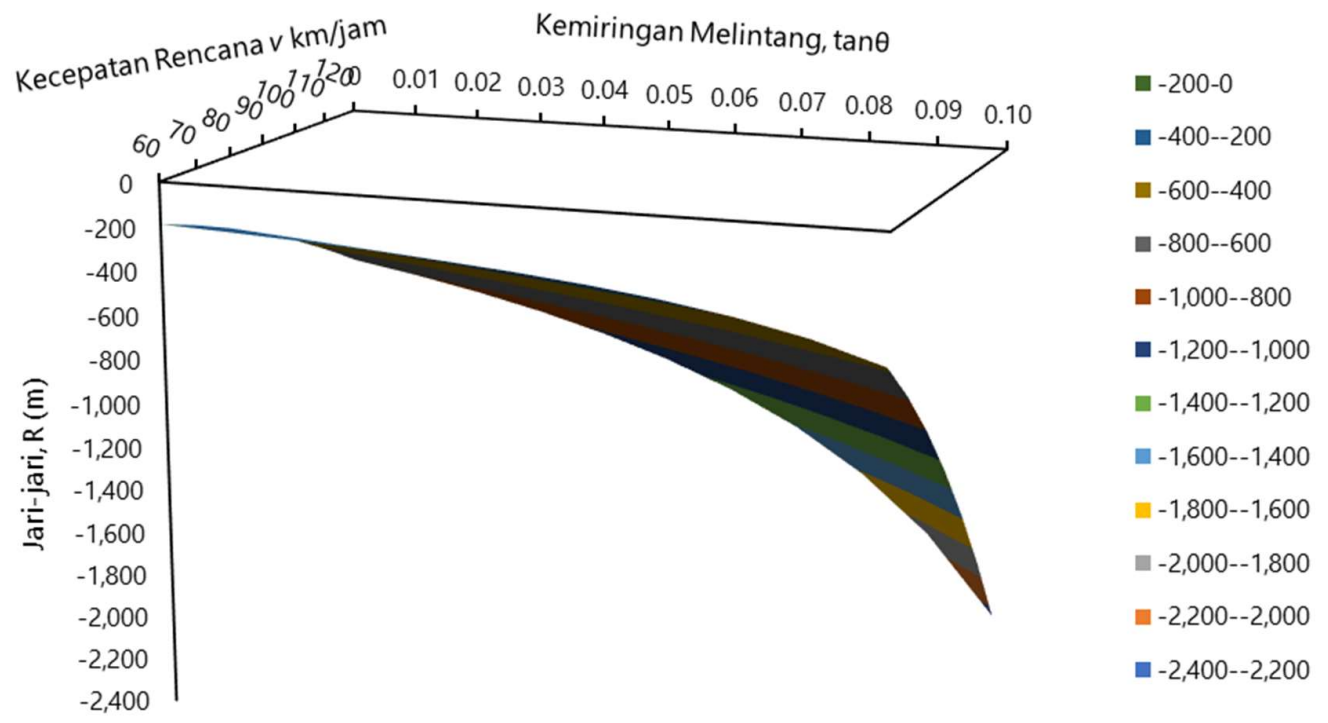

Gambar 2. Grafik simulasi gerak kendaraan yang menikung dengan kecepatan minimum; hubungan $R, v, \tan \theta$, pada $\mu_{s}$ tetap. 
Jari-jari, $R(\mathrm{~m})$

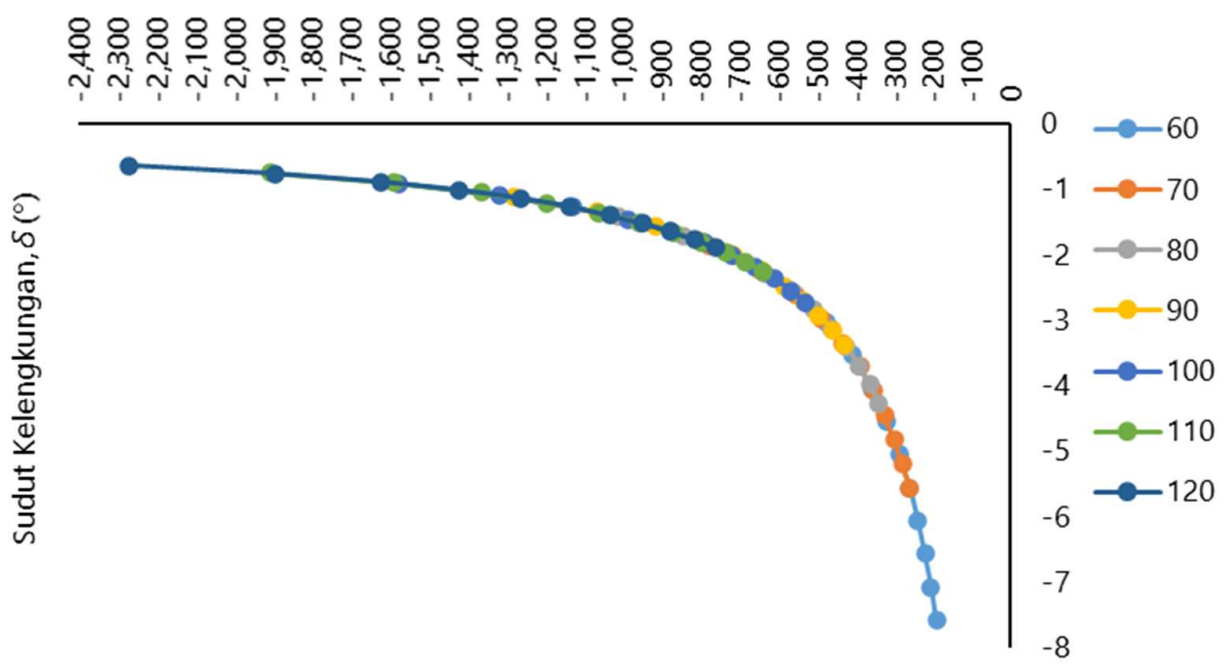

Gambar 3. Grafik simulasi gerak kendaraan yang menikung dengan kecepatan minimum; hubungan $R$ dan $\delta$.

Pendekatan dalam perancangan geometri lengkung jalan dengan menganggap hasil kali koefisien gesekan melintang $\left(\mu_{s}\right)$ dan kemiringan melintang $(\tan \theta)$ kecil sehingga nilai $\left(1+\mu_{s} \cdot \tan \theta\right)$ dapat diabaikan, memberikan nilai jari-jari tikungan $(R)$ dan derajat kelengkungan $(\delta)$ negatif yang diperlihatkan Gambar 2 dan 3, sehingga menjadi imajiner.

Hasil simulasi gerak kendaraan pada kecepatan rencana maksimum ditampilkan pada Gambar 4 dan 5 .

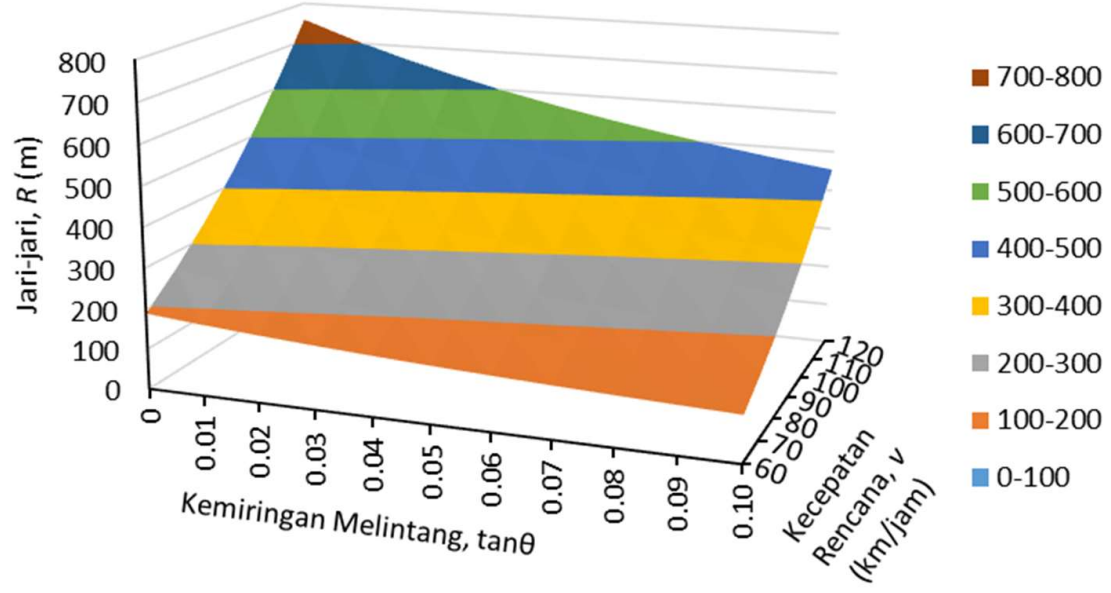

Gambar 4. Grafik simulasi gerak kendaraan yang menikung dengan kecepatan maksimum; hubungan $R, v, \tan \theta_{1}$ pada $\mu_{\mathrm{s}}$ tetap.

Gambar 4 menunjukkan bahwa pada koefisien gesekan melintang $\left(\mu_{s}\right)$ tetap, kendaraan yang bergerak makin cepat di sebuah tikungan memerlukan jari-jari tikungan $(R)$ yang besar. Agar kendaraan tidak slip keluar dari jalur maka jalan dibuat semakin miring. Kemiringan jalan menahan kekuatan gaya sentrifugal yang menyebabkan kendaraan slip. Berdasarkan data simulasi, pada kecepatan terendah $v$

\begin{tabular}{r|r|r}
\hline p-ISSN 2085-0409 & Berkala Fisika Indonesia : Jurnal IImiah Fisika, Pembelajaran dan Aplikasinya \\
e-ISSN 2550-0465 & Vol. 12 No. 2, Juli 2021 |33-39
\end{tabular}


$=60 \mathrm{~km} / \mathrm{jam}$ dan kemiringan melintang $\tan \theta=0$ (jalan datar) diperoleh jari-jari tikungan $R=188,98 \mathrm{~m}$.

Pada kecepatan tertinggi $v=120 \mathrm{~km} / \mathrm{jam}$ dan kemiringan melintang $\tan \theta=0$ jari-jari tikungan sebesar $R=755,91 \mathrm{~m}$. Jika jalan makin miring dimana $\tan \theta=0,1$ maka pada kecepatan terendah akan didapat $R=113,39 \mathrm{~m}$ dan $R=453,54 \mathrm{~m}$ di kecepatan tertinggi. Data ini memperlihatkan kemiringan jalan merupakan faktor penting dalam perancangan geometri lengkung yang berfungsi menjaga keselamatan kendaraan saat bergerak dengan kecepatan tinggi di sebuah tikungan.

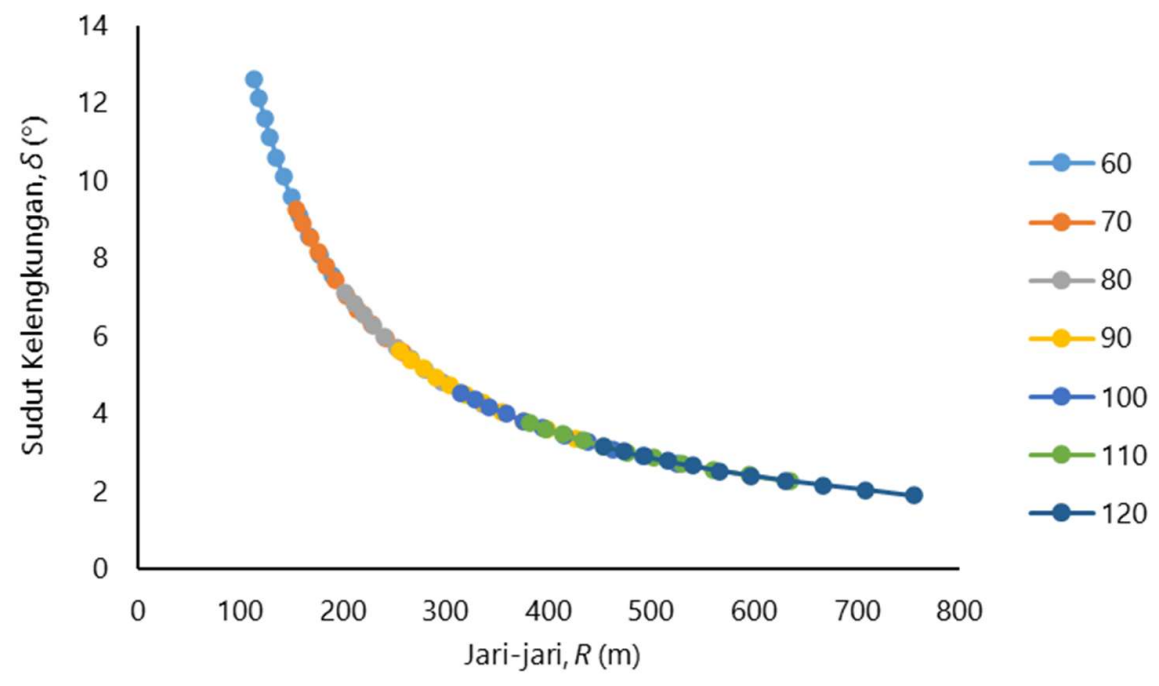

Gambar 5. Grafik simulasi gerak kendaraan yang menikung dengan kecepatan maksimum; hubungan $R$ dan $\delta$.

Gambar 5 memperlihatkan hubungan jari-jari tikungan $(R)$ dan derajat kelengkungan $(\delta)$, di mana $R$ yang panjang untuk $\delta$ yang kecil. Dalam penerapan praktis, interchange yang dapat dilewati kendaraan dengan kecepatan tinggi (120 km/jam) berada di tol luar kota. Kendaraan yang melewati tol dalam kota biasanya bergerak dengan kecepatan rata-rata aman 60-80 km/jam ketika melalui interchange.

Kecepatan minimum hampir tidak menjadi perhatian dalam perancangan geometri lengkung jalan tol. Hal ini sesuai dengan tujuan dibangunnya jalan tol atau jalan bebas hambatan adalah untuk mempersingkat waktu perjalanan kendaraan dari satu daerah ke daerah lain.

\section{Simpulan}

Simulasi gerak kendaraan pada kecepatan minimum dengan asumsi adanya pengaruh gaya sentripetal (menuju pusat tikungan) dan gaya gesek ban dengan permukaan jalan (berarah keluar menjauhi pusat tikungan) memberikan hasil yang imajiner. Simulasi gerak kendaraan pada kecepatan maksimum dengan asumsi adanya pengaruh gaya sentrifugal (menjauhi pusat tikungan) dan gaya gesek ban dengan permukaan jalan (mendekati pusat tikungan) memberikan hasil yang nyata dan digunakan dalam perancangan geometri lengkung jalan. Pada koefisien gesekan melintang $\left(\mu_{s}\right)$ tetap, kendaraan yang bergerak makin cepat di sebuah tikungan memerlukan jari-jari tikungan $(R)$ yang besar. Agar 
kendaraan tidak slip keluar dari jalur maka jalan dibuat semakin miring. Kemiringan jalan menahan kekuatan gaya sentrifugal yang dapat menyebabkan kendaraan mengalami slip.

\section{Referensi}

Adnan, N. R. N., Pranoto, \& Rahardjo, B. (2020). Analisis kondisi geometrik jalan terhadap potensi terjadinya kecelakaan lalu lintas. Jurnal Bangunan, 25(1), 21-32.

Arbaiyah, Lumba, P., \& Fahmi, K. (2013). Analisis geometrik tikungan Padangluhong pasir pengaraian. Jurnal Mahasiswa Teknik UPP, 1(1), 1-6.

Bethary, R. T., Pradana, M. F., \& Indinar, M. B. (2016). Perencanaan geometrik jalan alternatif Palima-Curug (Studi kasus: Kota Serang). Jurnal Fondasii, 5(2), 12-21.

Bryniarska, Z., \& Zakowska, L. (2017). Multi-criteria evaluation of public transport interchanges. Transportation Research Procedia, 24, 25-32. https://doi.org/10.1016/j.trpro.2017.05.063

Erga Rahmada Fauzan, Thoriq, Y. A., Arifi, M. Z., \& Wicaksono, A. (2013). Kajian geometrik jalan raya pada bundaran arteri baru Porong Sidoarjo. Jurnal Mahasiswa Jurusan Teknik Sipil, 1(2), 1175-1190.

Intini, P., Berloco, N., Colonna, P., Ottersland Granås, S., \& Olaussen Ryeng, E. (2019). Influence of Road Geometric Design Consistency on Familiar and Unfamiliar Drivers' Performances: Crash-Based Analysis. Transportation Research Record: Journal of the Transportation Research Board, 2673(10), 489-500.

Kaharu, F., Lalamentik, L. G. J., \& Manoppo, M. R. E. (2020). Evaluasi geometrik jalan pada ruas jalan trans sulawesi Manado-Gorontalo di desa Botumoputi sepanjang 3 km. Jurnal Sipil Statik, 8(3), 353-360.

Lucietti, L., Hoogendoorn, C., \& Cré, I. (2016). New Tools and Strategies for Design and Operation of Urban Transport Interchanges. Transportation Research Procedia, 14, 1240-1249.

McGee, K. G. H. and H. W. (1983). Driver perception-reaction time: Are revisions to current specification values in order? (No. HS-036 165).

Ng, J. C. ., \& Sayed, T. (2004). Effect of geometric design consistency on road safety. Canadian Journal of Civil Engineering, 31(2), 218-227.

Sinaga, L., Sendow, T. K., \& Waani, J. E. (2019). Evaluasi Geometrik Jalan Berdasarkan Standar Perencanaan Bina Marga. Jurnal Sipil Statik, 7(7).

Subkhan, M. F. (2019). Evaluasi Dan Perencanaan Ulang Desain Geometrik Jalan Berdasarkan Standart Bina Marga Pada Ruas Jalan Dadaprejo Kota Batu. PROKONS: Jurnal Teknik Sipil, 12(2), 79-84.

Sumarsono, A., Pramesti, F. P., \& Sarwono, D. (2010). Model Kecelakaan Lalulintas di Tikungan karena Pengaruh Konsistensi Alinyemen Horisontal dalam Desain Geometri Jalan Raya. Media Teknik Sipil, 10(2), 85-92.

Suwardo, Haryanto, I., \& Devi. (2018). Perancangan geometrik jalan: standar dan dasar-dasar perancangan (Cetakan ke). Gadjah Mada University Press, 2018. 